\title{
sUAS for 3D Tree Surveying: Comparative Experiments on a Closed-Canopy Earthen Dam
}

\author{
Cuizhen Wang*(D), Grayson Morgan (D) and Michael E. Hodgson \\ Department of Geography, University of South Carolina, Columbia, SC 29208, USA; \\ morgangr@email.sc.edu (G.M.); hodgsonm@sc.edu (M.E.H.) \\ * Correspondence: cwang@mailbox.sc.edu
}

Citation: Wang, C.; Morgan, G.; Hodgson, M.E. sUAS for 3D Tree Surveying: Comparative Experiments on a Closed-Canopy Earthen Dam. Forests 2021, 12, 659. https://doi.org/ $10.3390 /$ f12060659

Academic Editor: John Couture

Received: 20 April 2021

Accepted: 17 May 2021

Published: 22 May 2021

Publisher's Note: MDPI stays neutral with regard to jurisdictional claims in published maps and institutional affiliations.

Copyright: (c) 2021 by the authors. Licensee MDPI, Basel, Switzerland. This article is an open access article distributed under the terms and conditions of the Creative Commons Attribution (CC BY) license (https:// creativecommons.org/licenses/by/ $4.0 /)$.

\begin{abstract}
Defined as "personal remote sensing", small unmanned aircraft systems (sUAS) have been increasingly utilized for landscape mapping. This study tests a sUAS procedure of 3D tree surveying of a closed-canopy woodland on an earthen dam. Three DJI drones-Mavic Pro, Phantom 4 Pro, and M100/RedEdge-M assembly-were used to collect imagery in six missions in 2019-2020. A canopy height model was built from the sUAS-extracted point cloud and LiDAR bare earth surface. Treetops were delineated in a variable-sized local maxima filter, and tree crowns were outlined via inverted watershed segmentation. The outputs include a tree inventory that contains 238 to 284 trees (location, tree height, crown polygon), varying among missions. The comparative analysis revealed that the M100/RedEdge-M at a higher flight altitude achieved the best performance in tree height measurement $($ RMSE $=1 \mathrm{~m}$ ). However, despite lower accuracy, the Phantom 4 Pro is recommended as an optimal drone for operational tree surveying because of its low cost and easy deployment. This study reveals that sUAS have good potential for operational deployment to assess tree overgrowth toward dam remediation solutions. With 3D imaging, sUAS remote sensing can be counted as a reliable, consumer-oriented tool for monitoring our ever-changing environment.
\end{abstract}

Keywords: sUAS; personal remote sensing; point cloud; watershed segmentation; 3D tree inventory

\section{Introduction}

Dams provide beneficial functions such as flood control and reliable water supplies in our living environments. Around 65\% of U.S. dams are privately owned earthen dams that are aging and lacking maintenance [1]. As hurricanes and tropical storms on the Atlantic coast are reportedly occurring more frequently in a warmer climate [2,3], earthen dams raise high concerns about their hydraulic stability against severe wind and heavy precipitation during extreme weather events. Dam failures may have monumental repercussions, with dramatic consequences such as loss of life and severe damage to property. The failure of over 70 regulated dams in South Carolina (SC) as a result of back-to-back hurricanesJoaquin in October 2015 and Matthew in October 2016-is an illustrative example of the human-environment consequences of dam breaches $[4,5]$.

Trees growing on dam slopes are one of the more controversial factors contributing to dam failures. In 2000, the Association of State Dam Safety Officials (ASDSO) reported that about $50 \%$ of state-regulated dams in 48 U.S. states had excessive tree growth [6]. South Carolina, for example, has 2249 regulated dams, and $60-80 \%$ of these dams have trees. Green cover helps to stabilize soil mass on dam slopes and to reduce erosion from overtopping when the water level rises. However, old-growth tree roots loosen the soil mass and create root cavities, allowing more water into the dam, which can lead to seepage failure [6]. An earthen dam can be characterized in different zones: upstream slope, crest, and downstream slope. The impact of trees growing on dam slopes varies with their size, health, and location. For example, large trees on the lower downstream toe area below the seepage line are of greater concern than similarly sized trees on the upper downstream area. 
Dam owners are required to remove trees with high impact on dam safety, and quantitative tree survey records on dams are necessary for decision making. Walkthroughs (i.e., in situ surveys of the dam) are currently the primary means of tree inspection. However, walkthroughs of thousands of dams in a state are time consuming, costly, and difficult to access, especially in cases of tree overgrowth on earthen dams.

Very-high-resolution (VHR) remote sensing provides a promising way of collecting and documenting vegetation metrics for field engineers. Earthen dams are generally small in size. For example, the SC state-regulated dams could be as small as 25 feet high from the natural bed of the stream, with 50 acre-feet impoundment capacity [5]. Dam crests are often a few feet wide and 100 to 200 feet long. The meter/sub-meter-level VHR optical imagery is typically not adequate and considerably costly for systematic tree surveys on dams. LiDAR emits laser pulses to collect a 3D point cloud, and is considered to be superior for measuring forest environments [7,8]. Today, LiDAR data products have been collected in almost every county across the United States. However, airborne LiDAR instruments are costly and operationally difficult for repetitive data collection. In SC, a state-wide aerial LiDAR data collection program for all 46 counties was initiated in 2007, and completed 10 years later in 2017 [9]. The roughly 1.4-meter observation spacing is also inadequate for characterizing and monitoring trees on small earthen dams.

Defined as "personal remote sensing" [10], small unmanned aircraft systems (sUAS), or drones, have been increasingly utilized for timely surveillance at centimeter-level spatial resolutions. Rapid development of sUAS technology has equipped drones with increased capabilities of payload, sensors, and flight time, allowing them to accomplish a variety of missions in the field [11]. Recent advancements in computer vision and photogrammetry demonstrate their capabilities of quantitative information extraction, and automated photogrammetric algorithms have been made available in sUAS data analysis packages. The most commonly utilized processing approaches are the structure from motion (SfM) and multi-view stereo (MVS) techniques, which provide the 3D reconstruction of the landscape from a flight mission. The SfM technique builds an orthomosaic from the highly overlapping 2D images in a redundant bundle adjustment procedure [12,13], while the MVS approach develops a complete 3D topographic model from images taken at known camera viewpoints [14]. Relying on these techniques, both orthoimage and point cloud are extracted.

The 3D landscape contains advanced spatial details for quantitative tree surveying and cost-efficient inventory. In this respect, intensive studies have been conducted utilizing airborne LiDAR data. Hyyppä et al. [15] provided a comprehensive review of earlier efforts at LiDAR-based forest inventory extraction in boreal forests. Amiri et al. [8] examined a clustering-based 3D segmentation of the canopy height model (CHM) from full waveform airborne laser scanning (ALS) point clouds, in order to extract the regeneration coverage of a multilayer temperate forest. Dalponte et al. [16] reported that ALS outperforms hyperspectral imagery in delineating individual tree crowns. Aside from surveying tree crowns, ALS is superior in extracting tree height for a tree inventory. Ferraz et al. [17] applied a mean-shift-based statistical approach to segmenting ALS point clouds into overstory and understory, and extracted tree height and canopy base height from the extracted CHM in each layer. Later, this approach was updated, and applied to estimating the aboveground biomass in a tropical forest [18]. These studies reveal that LiDAR-based tree surveying, if the point density is high, could achieve similar accuracy to groundbased inventories.

sUAS point clouds for tree surveying have emerged as a possible alternative to, or augmentation of, ALS in recent years. Similar to the CHM-oriented LiDAR studies (e.g., [19]), a local maxima algorithm is commonly used to detect individual treetops, and a watershed segmentation is used to extract tree crown area [20,21]. Dong et al. [22] extracted individual tree crown areas in an orchard from a point cloud extracted from DJI Mavic 2 Pro imagery, which reached an overall accuracy of $0.26-0.39 \mathrm{~m}$ in tree height and $0.48-0.72 \mathrm{~m}^{2}$ in crown area. These studies were conducted in open-canopy forests, where individual 
crowns visually stood out. Coniferous trees were also easier to detect in sUAS point clouds due to their pointy shapes [20]. In areas of tree overgrowth into closed canopies, image calibration and individual tree detection may be problematic in sUAS missions.

This study aims to test the feasibility and procedure of sUAS-based tree surveying in closed-canopy woodlands. An earthen dam experiencing tree overgrowth in Lexington County, SC was selected as the study site. Three DJI drones-Mavic Pro, Phantom 4 Pro, and Matrice100 (M100) assembled with the RedEdge-M multispectral sensor-were tested at various flight configurations. Orthoimages and point clouds were extracted in order to map trees and to delineate their heights and crown areas. While the performance varied among these drones, the study demonstrated that sUAS remote sensing may offer improved accuracy and efficiency over traditional walkthroughs for assessing tree overgrowth in support of dam remediation.

\section{Materials and Methods}

\subsection{Study Site}

The study site was the Sweet Bay Pond Dam, an earthen dam located 11 miles from downtown Columbia, South Carolina. This is a state-regulated C1 dam, meaning it has high hazard potential-likely loss of life and/or serious damage to infrastructure [6]. A lowoblique photo (Figure 1) taken by a Mavic Pro on 26 October 2019 reveals the overgrowth of trees into a closed canopy on the dam's downslope. It is difficult for field engineers to record all trees and inspect their impacts on the dam during a walkthrough.

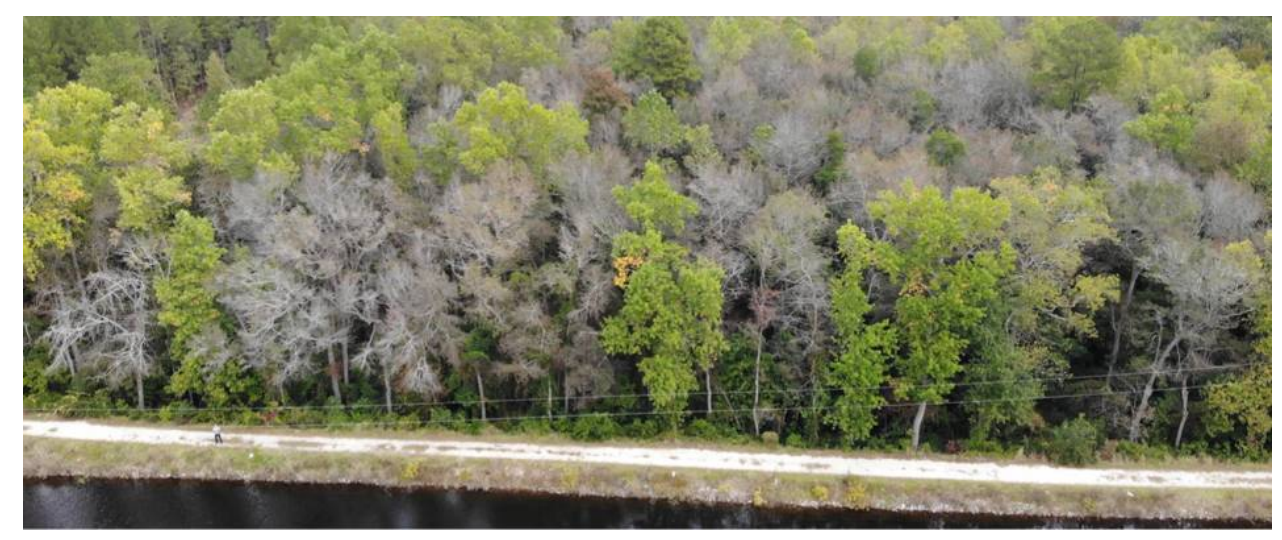

Figure 1. An oblique view of Sweet Bay Pond Dam in Lexington County, SC. This fall-season photo was taken with a Mavic Pro on 25 October 2019.

The dam crest is 180 meters long from the northwest entrance to the spillway at the southwest side. A large number of trees of different sizes grow on its downstream slope. Root cavities, especially from older trees, may cause erosion of soil mass and impact the dam's stability. The most common tree species is black gum (Nyssa sylvatica), which is senescent and leaf-off in Figure 1. Other common trees include tulip poplar (Liriodendron tulipifera) and loblolly pine (Pinus taeda), which remain green. Other trees species are limited.

\subsection{Drone Flights and Data Sets}

In 2019-2020, we launched multiple sUAS flights over the dam and collected centimeterlevel true color and color infrared images using the three DJI drones. The Mavic Pro has a built-in FC220 camera (true color $4000 \times 3000$ ), while the Phantom 4 Pro has a built-in FC6310 (true color $4864 \times 3648$ ). The M100 is assembled with a MicaSense RedEdge-M multispectral sensor (5-band 1280 x 960): blue, green, red, red edge, and near-infrared (NIR).

Six flights were launched in four days over a two-year period (Table 1). For the autonomous flight missions, we used the DroneDeploy APP with the Mavic Pro and Phantom 4 Pro and the Atlas Flight APP for the M100/RedEdge-M. All flights were made 
between 11:00 a.m. and 1:00 p.m. on sunny days. Each flight was completed in 5-13 min without the need of changing batteries. The same launch site in the open space at the dam entrance was used, and the remote pilot was located at the launch site and satisfied the visual line of sight (VLOS) rule under the U.S. Federal Aviation Administration sUAS Part 107 regulation [23]. sUAS images were taken with 85\% endlap (along the path) and 80\% sidelap (cross the path). Five flights were set at sixty meters above ground level (AGL). The last flight, M100, on 22 September 2020, was at 90 m AGL, with all other flight parameters the same as M100 on 26 August 2020. Different flight path plans were also tested. As shown in Table 1, we tried all options (cross-grid, long-grid, and short-grid paths) for the Mavic Pro, the double-grid path for the Phantom 4 Pro, and the default short-grid path for the M100 missions. The Pix4DMapper package was used to process all sUAS images in this study. Two Mavic Pro flights, on 6 November 2019 and 26 August 2020, could not be satisfactorily calibrated. Their calibration rates, or the percentage of images calibrated in the mission, were $71 \%$ and $58 \%$, respectively. These two missions, one in long-grid and the other in short-grid plans, were not considered further in this study. As shown in Table 1, the flight areas of these missions were slightly different. For the purpose of comparison, we decided to survey all trees within 60 meters downward from the dam crest. A study polygon of 1.606 hectares $(\mathrm{Ha})$ was clipped from all missions.

Table 1. Six flight missions at the study site.

\begin{tabular}{|c|c|c|c|c|c|c|c|c|c|}
\hline Date & Drone & $\begin{array}{c}\text { Flight } \\
\text { Alt. (m) }\end{array}$ & $\begin{array}{c}\text { Flight } \\
\text { Path }\end{array}$ & Images & $\begin{array}{l}\text { Area } \\
\text { (ha) }\end{array}$ & $\begin{array}{l}\mathrm{GSD}^{1} \\
(\mathrm{~cm})\end{array}$ & $\underset{2}{\mathrm{GCP}}$ & $\begin{array}{c}\text { RMSE } \\
(\mathrm{cm})\end{array}$ & $\begin{array}{c}\text { Calib. } \\
\text { Rate }\end{array}$ \\
\hline $25 / 10 / 2019$ & Mavic Pro & 60 & Cross-grid & 141 & 2.62 & 1.96 & 10 & 2.8 & $95 \%$ \\
\hline \multirow[b]{2}{*}{ 06/11/2019 } & Mavic Pro & 60 & Long-grid & 195 & 2.33 & 1.92 & 8 & / & $71 \%$ \\
\hline & $\begin{array}{c}\text { Phantom } 4 \\
\text { Pro }\end{array}$ & 60 & $\begin{array}{l}\text { Double- } \\
\text { grid }\end{array}$ & 217 & 5.01 & 1.87 & 8 & 2.9 & $93 \%$ \\
\hline \multirow{2}{*}{$26 / 08 / 2020$} & Mavic Pro & 60 & Short-grid & 72 & 1.51 & 1.83 & 9 & / & $58 \%$ \\
\hline & M100 & 60 & Short-grid & $1280 *$ & 3.00 & 4.19 & 13 & 1.5 & $91 \%$ \\
\hline $22 / 09 / 2020$ & M100 & 90 & Short-grid & 1390 * & 4.08 & 5.41 & 9 & 3.1 & $92 \%$ \\
\hline
\end{tabular}

${ }^{1}$ GSD: ground sampling distance, or average pixel size of the orthoimage. ${ }^{2}$ GCP: ground control point. * Note: The M100/RedEdge-M images are recorded as single-band TIFF files.

A set of $12 " \times 12^{\prime \prime}$ black and white checker boards (vinyl tiles) were randomly set up across the study site to serve as our ground control points (GCPs). During each mission, 8-13 GCPs were collected using a survey-grade GNSS (Emlid Reach RS2) in real-time kinematic RTK mode. With one RS2 unit serving as the base (at least 2 hours recording in the field) and the other as a rover, the GCP recordings could reach about 2-cm-level accuracy after precise point positioning (PPP) correction services, such as the Online Positioning User Service (OPUS) at the NOAA National Geodetic Survey [24,25]. GCPs within the closed-canopy woodland were not available. The GCPs were applied in the orthomosaic and point cloud process in the Pix4DMapper package, and the resulting horizontal rootmean-square errors (RMSEs) were within 1.5 to $3 \mathrm{~cm}$, roughly 1 to 1.5 pixels of the extracted orthoimages (as shown in Table 1). These RMSEs reasonably depict the $(x, y)$ locational accuracy of the orthoimages and point clouds of each flight. The vertical (z) accuracy was evaluated using selected points on the flat dam crest.

Trees on the dam slope grow into a closed-canopy, and are covered with dense understory shrubs, making it difficult to walk through for field survey. The lack of open space also restricts the measurement of tree height with the commonly used laser rangefinders. For validation purposes, we selected a strip of trees along the road nearby to serve as our validation site. On 27 September 2020, all of the 62 trees at this site were measured using a handheld Nikon Forestry Pro. These field measurements served as ground truth to evaluate sUAS performance in estimating tree height. Only the M100/RedEdge-M mission was conducted at this validation site.

The LiDAR point cloud was downloaded from the U.S. Geological Survey (USGS) National Geospatial Program [26] in order to build a bare-earth model of the study site. 
The LiDAR data for Lexington County, SC were acquired in 2010 at a $1.4 \mathrm{~m}$ nominal point spacing and $18 \mathrm{~cm}$ vertical accuracy (RMSE) [27]. In accordance with LiDAR Base Specification V2.0 [28], the released USGS LiDAR products have been classified as ground, low/medium/high vegetation, building, road surface, water, etc. The LiDAR dataset at the study site contained 38,695 points (Table 2). Visually referencing with the sUAS orthoimages, we combined the LiDAR points classified as ground, model key, and road to represent the bare-earth surface. This "bare earth" set contained $26.40 \%$ of the original LiDAR points at the study site. The majority of the dataset $(73.42 \%)$ was coded as unclassified, mostly consisting of tall and short vegetation in the woodland.

Table 2. Statistics of the USGS point cloud at the study site. The $z$ value is the AGL height.

\begin{tabular}{ccccccc}
\hline Code & Class & Points & Percent & z_min & z_max & $\begin{array}{c}\text { Interpreted Land } \\
\text { Cover }\end{array}$ \\
\hline 1 & Unclassified & 28,411 & $73.42 \%$ & 48.61 & 78.69 & Vegetation \\
\hline 2 & Ground & 9063 & $23.42 \%$ & 48.43 & 52.65 & Bare earth \\
\hline 8 & Model key & 922 & $2.38 \%$ & 48.43 & 52.70 & Bare earth \\
\hline 11 & $\begin{array}{c}\text { Road } \\
\text { Surface }\end{array}$ & 232 & $0.60 \%$ & 48.61 & 51.90 & Bare earth \\
\hline 3,9 & Other & 67 & $0.17 \%$ & 50.45 & 52.33 & Water, low veg \\
\hline \multicolumn{2}{r}{ Total points } & 38,695 & $100 \%$ & & & \\
\hline
\end{tabular}

\subsection{Approaches}

For each flight mission, the sUAS orthoimage and point cloud were created with the Pix4DMapper package using the default settings of image scale: full image size in the initial processing and $\frac{1}{2}$ image size in point cloud densification. Individual trees were identified, and tree heights and crown polygons were extracted. To evaluate the performance of the different missions, the point clouds were compared with LiDAR elevation on the dam crest at the study site, and the extracted tree heights were compared with field measurements at the validation site.

\subsubsection{Building sUAS Orthoimages and Point Clouds}

All sUAS images in each mission were calibrated in the Pix4DMapper package using the collected GCPs (as shown in Table 1). Similar to other automated photogrammetric algorithms, Pix4DMapper employs the structure from motion (SfM) technique to build the 3D view of the mission area. Individual images were mosaicked, geocorrected, and orthorectified with the resolved 3D perception. The created orthoimage holds a nadir view of the landscape. The ground sampling distance (GSD) of each orthoimage is listed in Table 1. The cm-level pixel size provides sufficient detail for tree surveying. The point cloud is a collection of 3D mass points $(x, y, z)$ representing the landscape. At $\mathrm{cm}$-level spacing intervals, this is expected to reveal more detailed 3D information than USGS LiDAR data.

\subsubsection{Extracting Digital Terrain and Canopy Height}

The digital surface model (DSM) and digital terrain model (DTM) are needed to extract canopy height [10]. The DSM represents the elevation of land cover above ground, such as canopy tops of trees or rooftops of buildings. The DSM can be easily created from the sUAS point cloud. The DTM represents the elevation of the bare-earth surface. Since sUAS 3D perception relies on photogrammetry, its point cloud only contains a single return ( $z$ value) at a $(x, y)$ location. In woodlands, the ground surface under the canopy is often not visible. Therefore, it is difficult to extract the "ground" points.

We used the USGS LiDAR point cloud to create the DTM. While the LiDAR data have a nominal point spacing of $1.4 \mathrm{~m}$, they allow multiple $x-y-z$ returns from a single pulse owning to the laser signal's strong penetration capacity. As shown in Table 2, LiDAR points 
coded as ground, model key, and road surface were extracted in a range of 48.43 to $52.70 \mathrm{~m}$ ASL. As the earthen dam surface slope was well behaved, these LiDAR ground returns were deemed to be highly representative of the ground elevation.

With the LiDAR point cloud (ground returns) and sUAS point cloud (all returns), the DTM and DSM were built in a triangulated irregular network (TIN) process. For the purpose of comparison, both the DTM and the DSM in all missions were resampled to a $20 \mathrm{~cm}$ cell size. The canopy height model (CHM) was thus created as [29]:

$$
\mathrm{CHM}=\mathrm{DSM}-\mathrm{DTM}
$$

The CHM is a raster layer of canopy height that represents the height of the topmost components above the ground surface.

\subsubsection{Tree Surveying: Tree Height, Treetops, and Crowns}

Based on plot-based measurements from a U.S. Forest Service research paper [30], most 10-year-old hardwood saplings in the Appalachian upland hardwood forest are 3 to $10 \mathrm{~m}$ high, varying with species and clearcut openings. Here we consider trees less than $10 \mathrm{~m}$ high to be saplings. All pixels within the CHM of less than $10 \mathrm{~m}$ were not considered in the following analysis, because trees in this earlier stage of growth are usually not a concern for dam safety.

The topmost point of an individual tree (treetop) in the CHM was identified using a variable-sized window filter [31]. This approach identifies the local maxima with a height-dependent crown searching window. These local maxima represent the treetops of individual trees. Geographically, our study site in the Midlands of SC is located at the southern end of the Piedmont region. It bears the same biophysical similarity of trees as in the work of [31]. For this reason, this study adopts their tree height-crown relationship (units in meters):

$$
\text { Crown Width }=2.515+0.009 \times \mathrm{CHM}^{2}
$$

Equation (2) defines the searching window at a given pixel, which varies with tree height at this pixel. A circular searching window was used. Only pixels with a CHM greater than $10 \mathrm{~m}$ were counted. Within this filter, the central pixel is compared with all other pixels in the window, and is defined as a local maximum if it presents the highest value.

Tree crowns in the CHM were outlined using a generalized marker-controlled watershed segmentation (MCWS) approach [32]. Tree crown is defined as a dominant clump of tree foliage and branches associated with a single treetop. This assumes that a tree crown follows the mathematical morphology of an inverted "watershed" [33]. Taking an inverted treetop as the bottom of the basin, the model can be simulated via a process of filling water until water overflow. A watershed is thus established that defines an inverted tree crown. Relying on the above extracted treetops, the MCWS approach divides the CHM layer into individual tree crowns at the study site. One crown is associated with one treetop. Therefore, some trees may not be identified where trees grow in clusters, and crowns overlap one another.

\subsubsection{Comparison Analysis and Validation}

The sUAS performances of the four missions were compared in several respects. The first comparison was the vertical (z) accuracy. A strip of sand-clay dam crest was outlined and taken as a stable surface during the missions. Counting the LiDAR point clouds as trustful elevation sources, all points on the strip were extracted to test the comparability of the sUAS point clouds against LiDAR. A total of $27 \mathrm{LiDAR}$ points were recorded on the strip. For a given LiDAR point, the nearest sUAS point within $5 \mathrm{~cm}$ spacing was extracted in order to build the LiDAR-sUAS sample pair. With the 27 samples, the mean absolute error (MAE) was calculated in order to evaluate the magnitude of the sUAS's deviation from 
LiDAR. The mean error (ME) was also calculated, which takes the directional deviation into consideration:

$$
\begin{gathered}
M A E=\frac{\sum_{j=1}^{n}\left|H_{j}^{e}-H_{j}^{g}\right|}{n} \\
M E=\frac{\sum_{j=1}^{n}\left(H_{j}^{e}-H_{j}^{g}\right)}{n}
\end{gathered}
$$

where $H_{j}^{e}$ and $H_{j}^{g}$ denote the sUAS-extracted and LiDAR-recorded z values, respectively. The term $n$ represents the sample numbers: $n=27$ in this study. A larger MAE but smaller ME value indicates that the sUAS measurements are affected by directional deviation from LiDAR elevation.

The second comparison was the $(x, y)$ locational accuracy. This cannot be directly compared among the four missions, because the study area does not have permanent ground control points. Assuming crown shapes do not change dramatically in a one-year period (October 2019-August 2020), it becomes reasonable to compare the (x,y) locations of treetop points in different flight missions. A total of 40 trees with apparent treetops and visually distinguishable crowns on the point cloud were randomly selected. The sUAS performance of different missions was intercompared with respect to locational variations. Note that the $\mathrm{CHM}$ has a $20 \mathrm{~cm}$ cell size, so larger deviations between the missions are to be expected. Additionally, one must be aware that this comparison is less quantitatively accurate, since treetop locations could be affected by new growth, wind, or other environmental conditions. However, it still provides meaningful information in assessing the capability of delineating individual trees in different missions.

Thirdly, at the validation site, the sUAS-extracted tree height was compared with field records for accuracy assessment. The RMSE was calculated:

$$
R M S E=\sqrt{\frac{\sum_{j=1}^{n}\left(H_{j}^{e}-H_{j}^{g}\right)^{2}}{n}}
$$

where $H_{j}^{e}$ and $H_{j}^{g}$ denote the sUAS-extracted and field-measured tree height, respectively. The term $n$ represents the total number of trees in the assessment.

The extracted tree crowns cannot be validated without ground reference data. Instead, the sUAS performance of crown extraction in different missions was visually compared against the orthoimages. At cm-level resolution, and with phenological variations in August-November, the orthoimages provide a reasonable level of detail for the visual interpretation of tree crowns.

\section{Results}

\subsection{Orthoimage and Point Cloud}

The spatial resolution and geocorrection RMSE of the orthoimages from the four missions are listed in Table 1 above. For simplicity, all orthoimages are resampled to a pixel size of $5 \mathrm{~cm}$. Hereafter, the Mavic Pro mission on 25 August 2019 is referred to as MP0825, the Phantom 4 Pro mission on 6 November 2019 as P41106, the M100/RedEdge-M mission on 25 October 2020 as RE1025, and the M100/RedEdge-M mission on 22 September 2020 as RE0922. Figure 2 displays the orthoimages in an August-November trajectory in 2019-2020. The MP0825 mission exhibits a jagged border at the far end of the dam's downslope. While the mission reaches a calibration rate of 95\% (as shown in Table 1), eight individual drone images along the east border are uncalibrated, resulting in data loss, as shown in the orthoimage. 


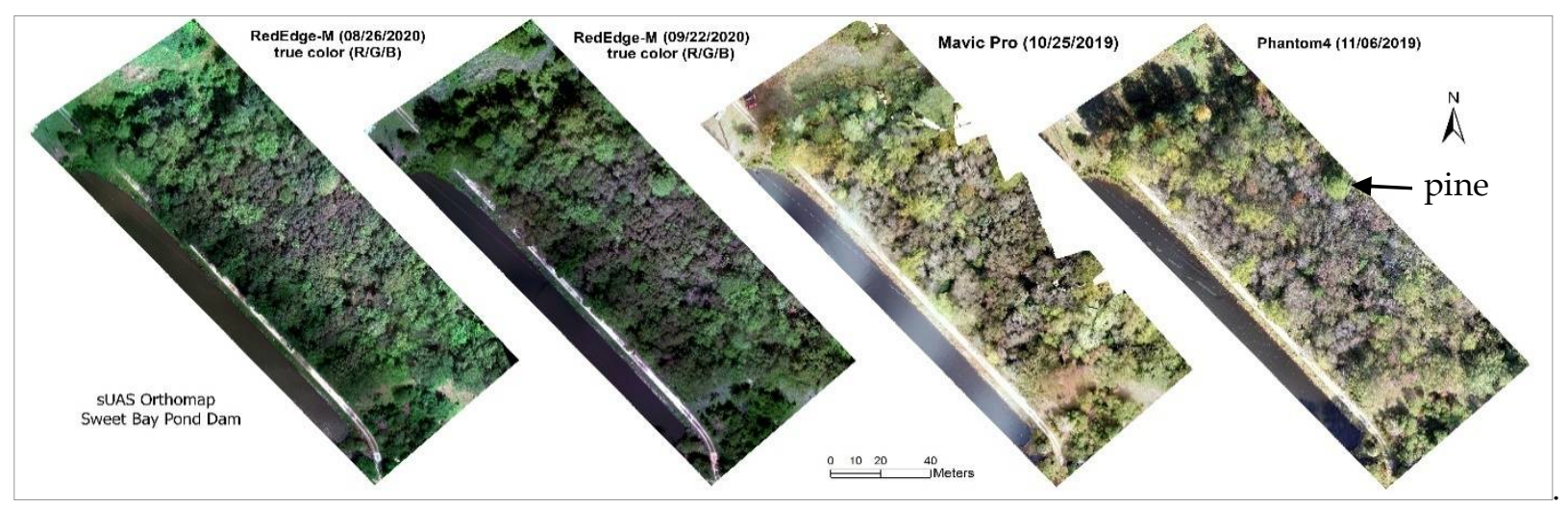

Figure 2. The orthoimages extracted from four flights (RE0826, RE0822, MP1025, and P41106).

The orthoimages clearly depict the overgrowth of trees that grow into a closed canopy at the study site. Individual tree crowns, especially those of tall trees, are still discernable. The images visually reveal different spectral and radiometric characteristics of their sensors. The RedEdge-M images are recorded in 16-bit, while the Mavic Pro and Phantom 4 Pro images are in 8-bit. In a true color view, the RedEdge-M images show a greener tone than those of Mavic Pro and Phantom4 Pro.

The four-stage orthoimage trajectory also reflects the phenological differences of tree species. For example, black gum has shiny, dark green leaves, and is sensitive to drought stress during the hot summers of SC. It starts to show early fall color in a dark brownish tone in August, which becomes more distinguishable in September. Its leaves are senescent and drop off in October-November. Tulip poplar remains green in summer (AugustSeptember), then shows its fall color in a yellowish green tone (October-November). Loblolly pine-for example, the one marked in Figure 2-has a large circular crown and remains evergreen, although it has a lighter tone in the Phantom 4 Pro image. These phenological variations help to delineate tree crowns in data analysis.

Trees grow on the downslope of the dam. The lowest elevation is in deep woodland at $48.4 \mathrm{~m}$ ASL. In the sUAS point clouds (Figure 3), all points below this threshold were counted as low noises, and were removed. The tallest point of canopy height is around $79 \mathrm{~m}$ ASL. The dam crest and open areas have low elevation with a dark blue tone in the point clouds. Shrubs and short trees surrounding the woodland have higher elevation in a lighter blue tone. The point clouds of the woodland are visually continuous due to their extremely high density, with cm-level spacing between points. Nevertheless, tall trees clearly stand out in a reddish tone and circular shapes. Interestingly, the electric power line above the water is clearly detected by all sUAS point clouds.

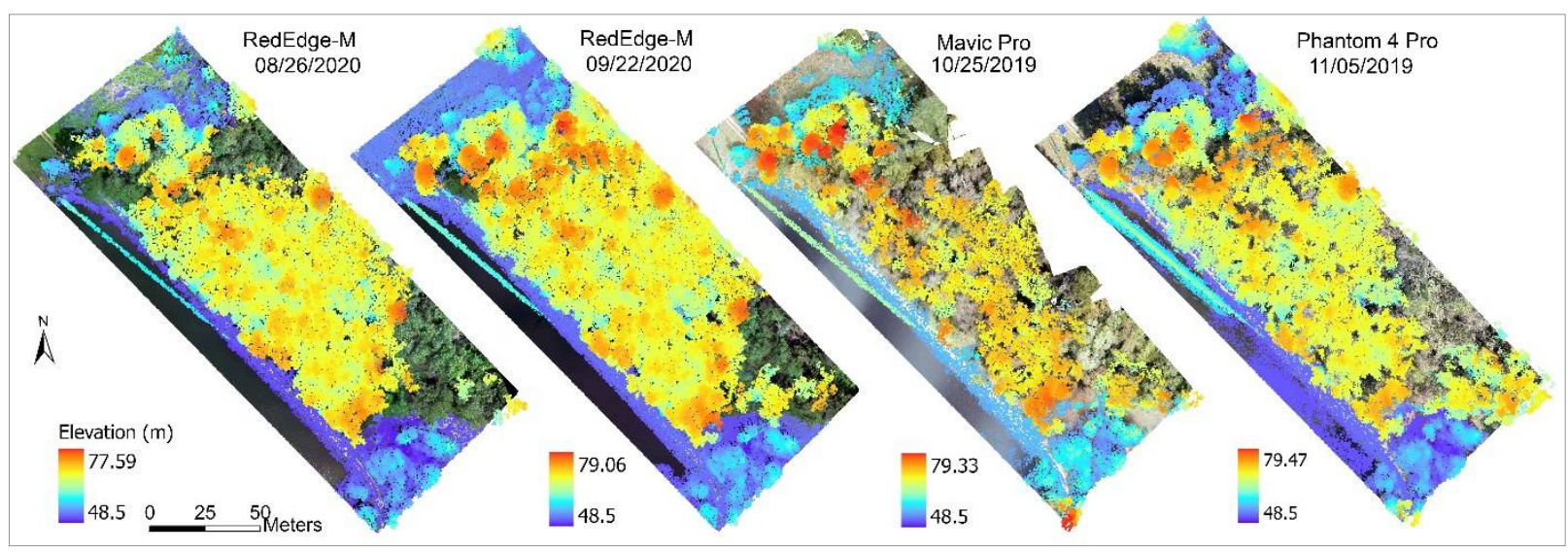

Figure 3. The height-colored point clouds extracted from four flights (RE0826, RE0822, MP1025, and P41106). 
Among the four flights, the MP1025 mission did not perform well. Data loss in its point cloud was more dramatic, leaving multiple large gaps within the woodland (Figure 3). The other three missions performed better, although data loss persistently remained, especially the large gap at the southeast end of the mission area. Overall, the RE0922 seems superior, with the largest coverage of its point cloud in the mission area. Given its poor performance in terms of both the calibration (noted earlier), orthoimage and point cloud, the MP1025 was not further examined in this study.

Within the same flight area polygon (1.606 ha), the USGIS LiDAR point cloud has a density of 2.41 points $/ \mathrm{m}^{2}$. Note that the LiDAR cloud may contain multiple returns at a point and, therefore, its horizontal density is even lower. sUAS point clouds only contain one point at each $x-y$ location. The P41106 point cloud has the highest density of 451.06 points $/ \mathrm{m}^{2}$, providing the most detail about tree canopies at the study site. At a flight height of $90 \mathrm{~m}$ AGL, the RE0922 point cloud reaches a density of 52.26 points $/ \mathrm{m}^{2}$, slightly lower than RE0826 (59.44 points $/ \mathrm{m}^{2}$ ) at $60 \mathrm{~m}$ AGL. Figure 4 demonstrates the improved coverage of sUAS mass points on an example pine tree. Within the tree crown outlined in the figure, only $32 \mathrm{LiDAR}$ points are collected in comparison with hundreds of RE0922 points. These dense sUAS points effectively reveal the tree's structural details.

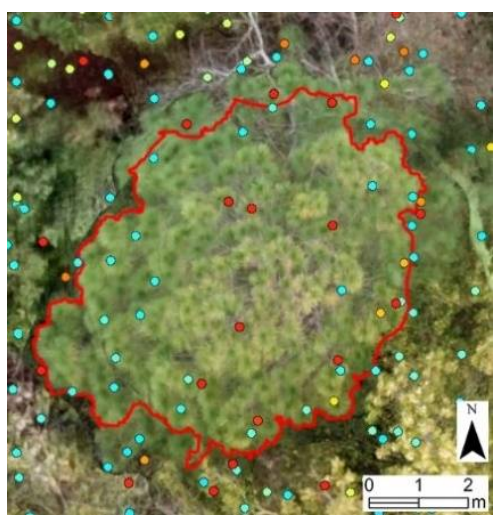

(a)

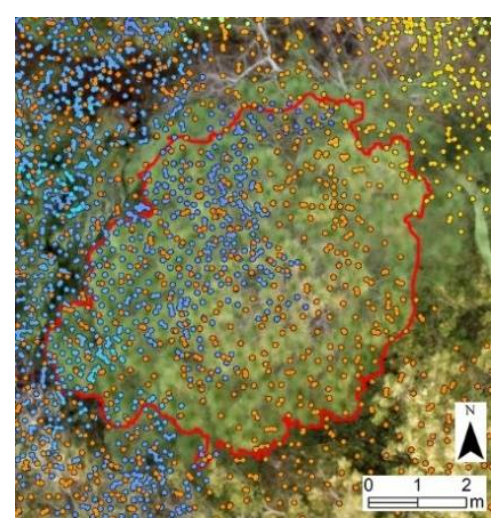

(b)

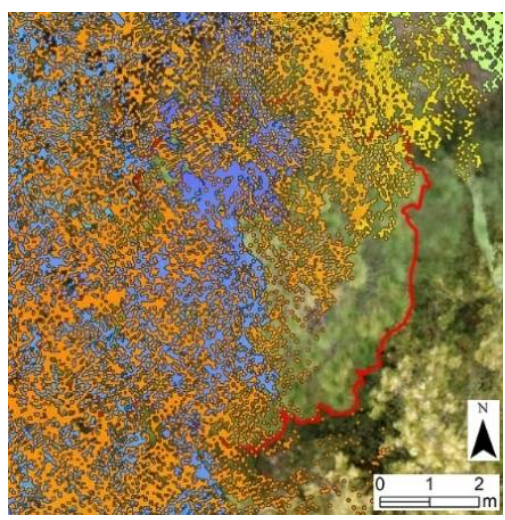

(c)

Figure 4. The 3D points of a pine tree extracted from LiDAR (a), RE0922 (b), and P41106 (c).

\subsection{Digital Terrain and $C H M$}

LiDAR bare-earth points have a much lower spatial density than the sUAS point cloud, but the sUAS points are generally of the overlying vegetation, and few represent the ground. The density of LIDAR ground points under the tree canopy of the woodland (Figure 5a) was quite adequate for representing the sloped earthen dam. In the created DTM (Figure 5b), the dam crest has a relatively higher elevation than its slope on both sides. The spillway is an important dam structure, which is clear at the south end of the study site (marked in the figure). The dam crest is relatively flat, at an average elevation of around $52 \mathrm{~m}$ ASL. The lowest elevation in the deep woodland is $48.4 \mathrm{~m}$, resulting in a maximum drop of $3.6 \mathrm{~m}$ from dam crest to downslope.

With the densely distributed sUAS point cloud, the extracted DSM of each mission reveals a high level of detail of the 3D tree canopies. Note that all raster layers, including DTM, DSM, and CHM, are at a $20 \mathrm{~cm}$ cell size. Figure 6 demonstrates the CHM layer from the RE0922 mission. Similar to the point cloud figure (Figure 3) above, the southwest end of the mission suffers from image calibration errors, and therefore, results in a large data gap. A smaller gap is also observed at the dam entrance in the northwest. The tallest point of the canopy is $29.69 \mathrm{~m}$. The inset of Figure 6 is the example pine tree (marked in Figure 2) with a 3D profile viewed from east to west (high oblique). The tree has an apparent distinguishable circular crown in the CHM. Clumps of shorter trees nearby are also detectable but grow together with a close canopy, reflecting a typical pattern of closed- 
canopy overgrowth. The sUAS point cloud only records the topmost points of the tree canopy layer. As opposed to LiDAR returns, ground points from the optical imagery under the canopy are not available. Therefore, the sUAS-extracted CHM is a thin, hollow 3D surface atop the tree canopy.

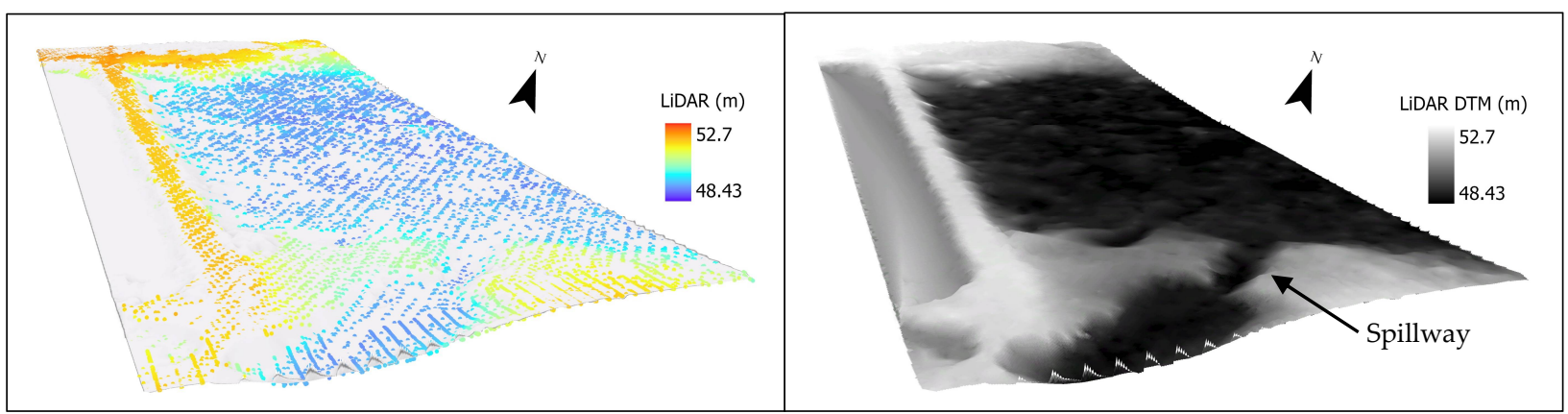

(a)

(b)

Figure 5. Bare-earth returns from the LiDAR point cloud (a) and the extracted DTM of the study site (b).

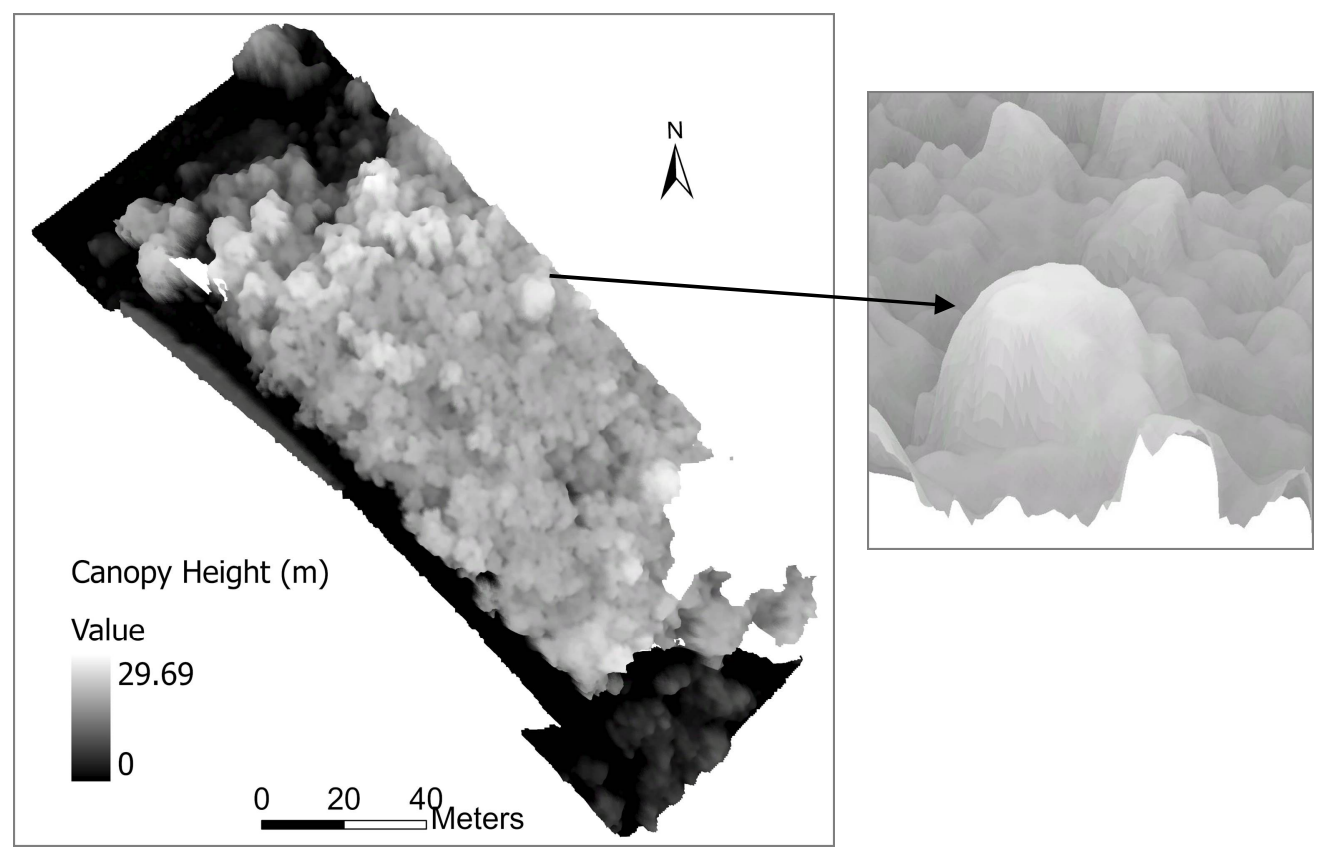

Figure 6. The CHM from the RE0922 mission. The inset shows a 3D view of the example pine tree.

\subsection{Treetop and Crown Delineation}

The sUAS point cloud and the extracted CHM allow the delineation of treetops and crowns from the continuous canopy cover. A treetop is a point with a local maximum in the CHM that represents the topmost point of a tree. One tree is assumed to have one treetop point. A threshold of CHM $>10 \mathrm{~m}$ is applied to all CHM layers. Figure 7 displays the 3D view of the treetops extracted from the RE0922 mission and its true color orthoimage. The vertical information (canopy height) is overlaid on the orthoimage to achieve a 3D perspective, which makes the tree clumps more outstanding. Treetops are marked as red columns emerging atop trees. The dam crest is flat in general, but some crest pixels are affected by canopy pixels above them, and are displayed as erroneously taller, white objects. 


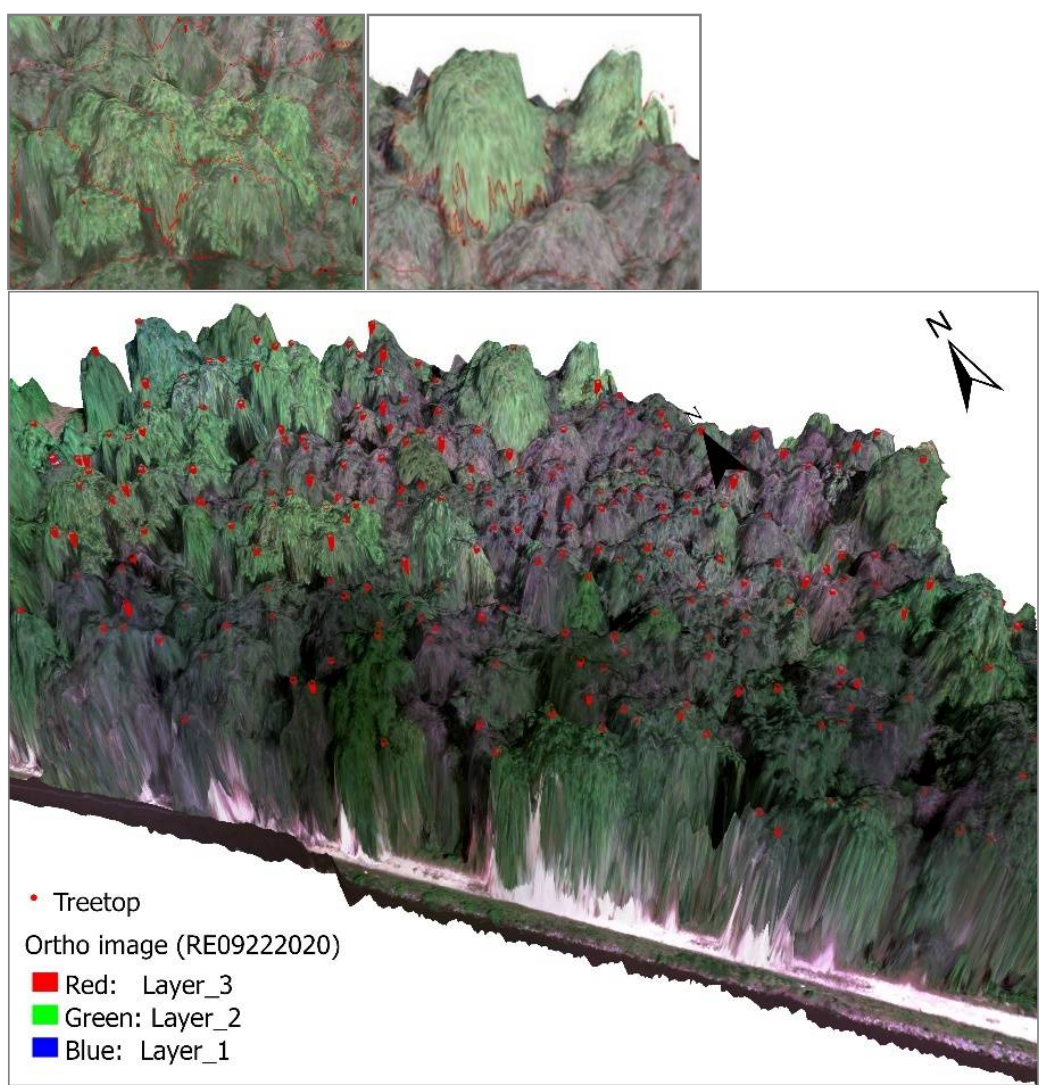

Figure 7. A 3D view of the RE0922 orthoimage embedded with treetops marked as red columns. Two insets show the $3 \mathrm{D}$ views of a pine tree and a tulip poplar cluster, respectively.

For the RE0922 mission, a total of 284 treetops were identified, with a height range of 12.3 to $29.69 \mathrm{~m}$. To reduce uncertainties in the extracted treetops and crowns, trees along the woodland borders and data gaps from calibration errors that did not contain complete crowns in the CHM were removed from the analysis. The two insets of Figure 7 display the $3 \mathrm{D}$ view of two example tree crowns. The one on the right is a pine tree that has a typical standalone, rounded crown. The one on the left is a green cluster of tulip poplars that grow together into a big clump. Multiple trees are successfully identified in this cluster, one with a treetop and a crown. It is reasonable, however, that some trees would not be detected if their treetops do not reveal identifiable local maxima.

Tree crowns are delineated from the joint marker-controlled watershed segmentation approach. One watershed segment is associated with a treetop point located in the watershed. For trees with relatively standalone crowns, crowns are extracted with regular shapes (similar lengths in major and minor axes). In areas where trees grow into close canopies, their crowns become irregularly shaped. As shown in the tulip poplar inset of Figure 7, the elongated crowns in the cluster may also indicate missing trees.

As revealed in the point clouds, all sUAS flights suffer from calibration-induced data gaps that vary according to systems and flight configurations. Treetops and crowns falling within or adjacent to these gaps could not be extracted. Figure 8 compares the treetops and crown polygons extracted from the three missions. It is clear that standalone trees-for example the example pine tree in previous figures-could be successfully extracted in all missions. However, the effectiveness in closed canopy areas varied among the three missions. Across the study site, 284 trees were identified in the RE0922 mission. The RE0826 mission produced 238 trees, suffering from higher calibration errors in the northeast and southeast areas of the study site. The P41106 mission extracted 251 trees, identifying more trees at the southeast end of the study area, where both RedEdge-M missions suffered from calibration errors. In deep woodland areas where tree canopies were closed, however, it 
identified fewer trees than the other missions. More detailed comparisons are described in the next section.

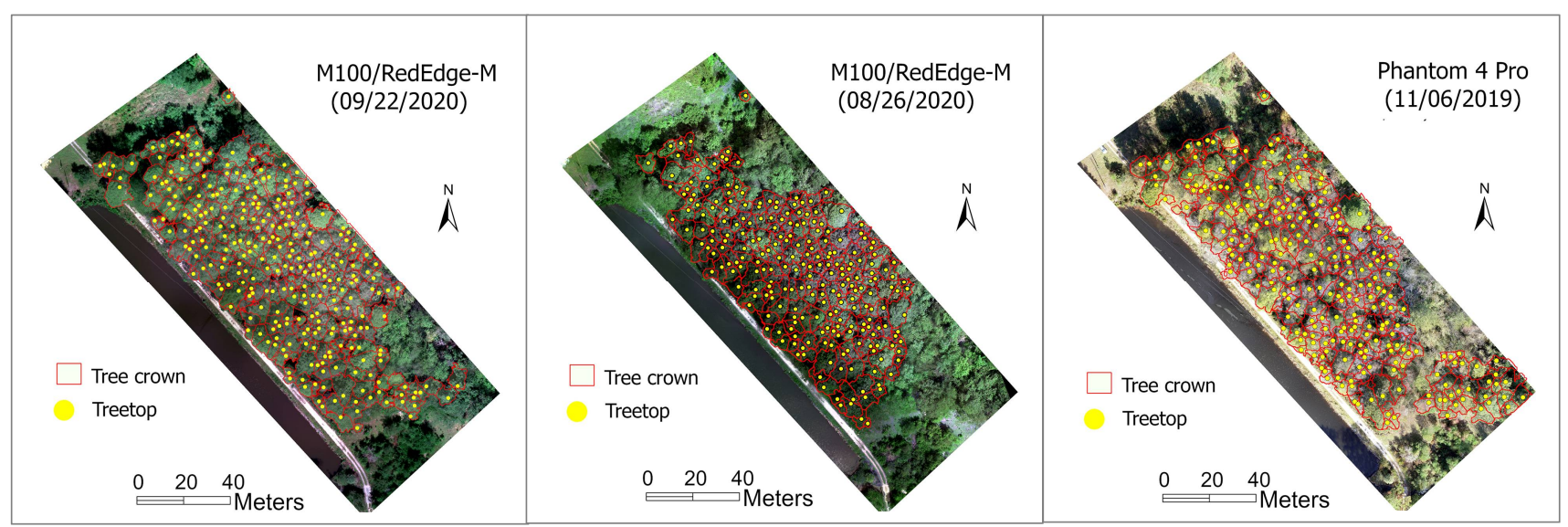

Figure 8. The extracted tree crowns and treetops from three missions (RE0922, RE0826, and P41106). One crown is associated with one treetop.

\subsection{Comparison and Accuracy Assessment \\ 3.4.1. Comparison of Elevation (z) Measurement against LiDAR}

Taking the LiDAR point cloud as the reference elevation source, the sUAS point clouds were compared against LiDAR on a strip of dam crest that was a considerably stable, permanent surface. The strip was flat, $15 \mathrm{~m}$ long and $1.5 \mathrm{~m}$ wide, containing 27 LiDAR points in an elevation range of 51.85 to $52.04 \mathrm{~m}$, with an average of $51.96 \mathrm{~m}$ ASL. Table 3 summarizes the three error metrics (MAE, ME, and RMSE) of the four sUAS missions.

Table 3. Locational comparison of the sUAS missions: elevation ASL (z) of the dam crest against LiDAR, and ( $x, y, C H M)$ of treetops against RE0922. All units are in $\mathrm{cm}$.

\begin{tabular}{|c|c|c|c|c|c|c|c|}
\hline \multicolumn{3}{|c|}{ sUAS Mission } & \multirow{2}{*}{$\begin{array}{c}\text { MP1025 } \\
8.32\end{array}$} & \multirow{2}{*}{$\begin{array}{c}\text { P41106 } \\
4.89\end{array}$} & \multirow{2}{*}{$\begin{array}{c}\text { RE0826 } \\
4.81\end{array}$} & \multirow{2}{*}{$\begin{array}{c}\text { RE0922 } \\
3.59\end{array}$} & \multirow[t]{2}{*}{$\begin{array}{c}\text { LiDAR } \\
\text { (2010) }\end{array}$} \\
\hline \multirow{3}{*}{ Dam crest $(n=27)$} & \multirow{3}{*}{$\mathrm{z}$} & MAE & & & & & \\
\hline & & $\mathrm{ME}$ & 7.41 & -0.05 & -4.81 & -1.71 & \multirow{2}{*}{ reference } \\
\hline & & RMSE & 13.38 & 6.39 & 5.45 & 4.65 & \\
\hline \multirow{9}{*}{ Treetop $(n=40)$} & \multirow{3}{*}{$\mathrm{x}$} & MAE & / & 37.0 & 26.25 & \multirow{9}{*}{ reference } & \multirow{9}{*}{ / } \\
\hline & & $\mathrm{ME}$ & / & 37.0 & -3.8 & & \\
\hline & & RMSE & / & 47.33 & 40.70 & & \\
\hline & & MAE & / & 61.5 & 26.9 & & \\
\hline & $\mathrm{y}$ & $\mathrm{ME}$ & / & -61.5 & 7.5 & & \\
\hline & & RMSE & / & 68.04 & 36.74 & & \\
\hline & \multirow{3}{*}{$\mathrm{CHM}$} & MAE & / & 36.8 & 14.59 & & \\
\hline & & $\mathrm{ME}$ & / & -22.05 & -0.72 & & \\
\hline & & RMSE & / & 46.21 & 19.78 & & \\
\hline
\end{tabular}

From the three error metrics, RE0922 has the best match with LiDAR in terms of elevation measurements with, an absolute deviation (MSE) of $3.59 \mathrm{~cm}$ and an RMSE of $4.65 \mathrm{~cm}$. This metric slightly underestimates (against LiDAR) the elevation, with a negative ME of $-1.71 \mathrm{~cm}$. P41106 has the lowest ME $(0.05 \mathrm{~cm})$, but a larger MSE of about $5 \mathrm{~cm}$, indicating both over- and underprediction biases. Table 3 also reveals that sUAS missions at higher flight altitudes produce better results. For all of the three error metrics, RE0826 at a $60 \mathrm{~m}$ flight altitude resulted in greater error than RE0922 at a $90 \mathrm{~m}$ altitude. With their RSME values in a range of 5 to $6 \mathrm{~cm}$, the RE0922, RE0826, and P41105 point clouds 
do not need to be adjusted in the $\mathrm{z}$ dimension. They can be directly used for DSM and CHM extraction.

Again, MP1025 has the largest deviation from LiDAR, confirming that its performance is not comparable with the Phantom 4 and M100/RedEdge-M missions.

\subsubsection{Locational and CHM Comparison of Treetops against RE0922}

To compare the relative positioning accuracies of the extracted trees in different missions, a total of 40 trees with visually distinguishable crowns were randomly selected in the woodland. The RE0922 was taken as a reference because it had a relatively higher accuracy in elevation and better point cloud coverage. Note that the comparison cannot be counted as an accuracy assessment because the treetops, defined as the topmost point in a local CHM window, may slightly vary in different missions.

The RE0826 had similar performance to the RE0922 mission, with low ME deviations of $(-3.8,7.58) \mathrm{cm}$ in the horizontal dimensions and $-0.72 \mathrm{~cm}$ in the CHM (Table 3). The MAE and RMSE were larger due to the impact of directional deviation and outliers. These errors were within 1 to 2 cells of the $20 \mathrm{~cm}$ CHM raster data, which reveals that the M100/RedEdge-M system has relatively stable accuracy in locational positions. For the Phantom 4 Pro, the absolute deviations of the extracted treetops were $(37.0,-61.5) \mathrm{cm}$ in the horizontal dimensions. The MAE values were the same as the ME, revealing a directional bias to the east and south. This could be as attributed to the system uncertainties between the two drones. The higher deviations in the $(\mathrm{x}, \mathrm{y})$ dimension may also arise from local environmental effects, such as wind and forage growth over the two years. The CHM measurements of P41106 were about $22.08 \mathrm{~cm}$ lower than RE0922 in terms of ME, although the other two errors were higher. The relative $\mathrm{CHM}$ deviations between the three missions were within 1 to $2 \mathrm{CHM}$ cells. The statistics in Table 3 indicates that both Phantom 4 Pro and M100/RedEdge-M are capable of tree height extraction.

\subsubsection{Visual Comparison of Treetop/Crown Extraction}

In a subset area of the woodland (Figure 9), most trees could be extracted from the three flights, although their treetop locations and crown boundaries were slightly shifted. The two RedEdge-M missions produced similar results in both treetop and crown delineation. In the Phantom 4 Pro mission, some trees could not be successfully identified. Thus, the tree crowns of the Phantom 4Pro mission were somewhat larger than those of the RedEdge-M missions.

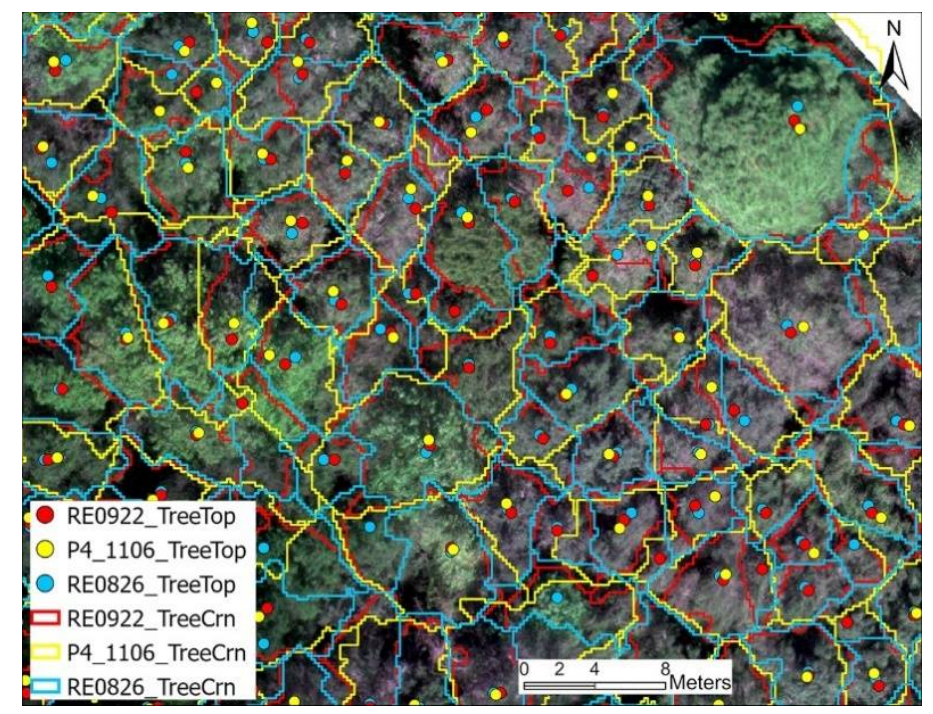

Figure 9. A subset area of the extracted tree crowns and treetops from the three missions. The background is the RE0922 orthoimage. 


\subsubsection{Accuracy Assessment of sUAS-Extracted Tree Height}

At the validation site, the sUAS-extracted (M100 only) tree heights were compared with field measurements using a laser rangefinder. The M100 flight was flown 7 days later than RE0922, using the same flight configuration; therefore, it can be counted as the validation of the RE0922 mission. Among the 62 trees at the site, 59 treetops were extracted. The scatterplot reveals a linear agreement between field-measured and sUAS-extracted tree heights with, a RMSE of $1 \mathrm{~m}$ (Figure 10). The correlation line (dashed) agrees with the 1:1 line. Both the MAE and ME measurements are within $1 \mathrm{~m}$.

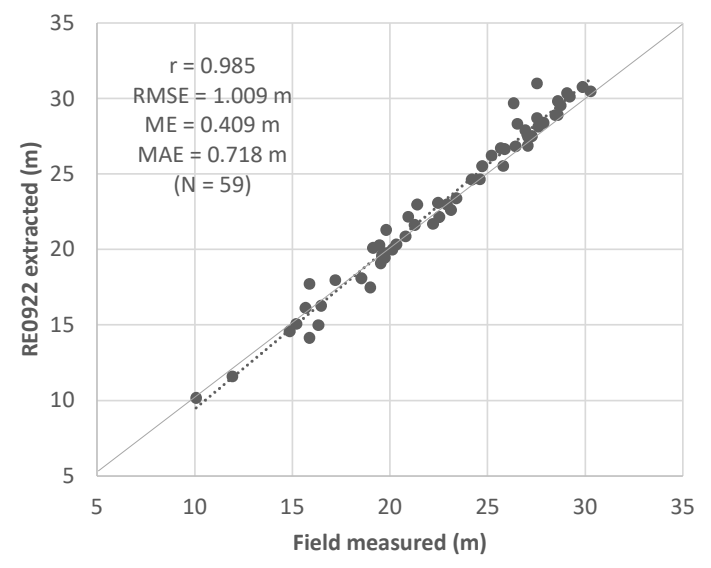

Figure 10. Scatterplot of the sUAS-extracted and field-measured tree heights (RE0922 only) at the validation site.

The RE0826 and P41106 missions were not tested at the validation site. In Table 3, their CHM comparisons against RE0922 at the study site have RMSE values of $0.462 \mathrm{~m}$ and $0.198 \mathrm{~m}$, respectively. All of these assessments indicate the feasibility of sUAS remote sensing for tree height extraction.

\section{Discussion}

sUAS have been commonly deployed for taking aerial photographs and videos for near-surface visual inspection. In July 2020, the U.S. Forest Service (USFS) released the procedure for UAS operation standards in order to promote the safe and lawful operation of sUAS in services including fire and natural resource management, in support of the USFS missions [34]. In respect of quantitative forest inventory, however, the low-cost drones have not been widely utilized for operational applications, due to their noisy image calibration and complicated image analysis procedures. This study tests the feasibility and comparison of several drones for 3D tree surveying in dense woodlands. Integrating the orthoimages and point clouds, the 3D canopy is reconstructed to identify trees and to measure their heights and crowns. Multiple flight attempts in our study show that the Mavic Pro was not reliable for tree surveying. Two of the three Mavic Pro missions could not achieve an acceptable calibration rate (Table 1), and the extracted point cloud from the third mission contains multiple large data gaps (Figure 3). Both the Phantom 4 Pro and the M100/RedEdge-M performed well in building orthoimages and point clouds for acceptable tree surveying. The M100/RedEdge-M (USD 8000 assembly cost) had the best agreement with LiDAR in the vertical dimension. However, the lighter weight Phantom 4 Pro (USD 1500 all-in-one package) may be a better fit if budget and system maintenance are considered for operational purposes. The sensor of the Mavic Pro is considerably smaller $(6.3 \times 4.7 \mathrm{~mm})$ than that of the Phantom 4 Pro $(13.2 \times 8.8 \mathrm{~mm})$, and thus, the sharpness of the resulting image is less. This loss of detail may have resulted in its somewhat poorer results. We expect the performance of the newer Mavic 2 Pro (same sensor as the Phantom 4 Pro) to be better, and comparable to that of the Phantom 4 drones. 
With intensively overlapping images taken from drones flying above the canopy, the 3D landscape can be obtained, which makes the sUAS imaging superior to the 2D view of high-resolution satellites or aerial remote sensing. In the vertical dimension, the low-cost drones and cameras may also outcompete LiDAR sensors in terms of affordability, accessibility, and operational efficiency. With drones flying up to $122 \mathrm{~m}(400 \mathrm{ft})$ above the ground, the orthoimage reaches $\mathrm{cm}$-level spatial resolution, and the point cloud contains much denser mass points of tree canopies than could be extracted from typical airborne LiDAR data. For the sUAS missions explored in this study, the RedEdge-M point clouds had more than 20 times the arithmetic density of 2.41 points $/ \mathrm{m}^{2}$ in the USGS LiDAR point cloud product. Moreover, sUAS offer the flexibility to launch missions quickly and efficiently in order to maximize time-critical data collection. Given the expenses and operational difficulties of the LiDAR mission, it is difficult to repeat and update its 3D data products. In this sense, sUAS have been counted as user-controlled remote sensing, or "personal remote sensing" as defined in current literature [10].

Despite these technical and operational advances, drawbacks of sUAS remote sensing are also obvious, as demonstrated in the study. Image calibration errors are a common issue for sUAS missions flying over dense forests where ground control targets are not visible. In our study, images from all three Phantom 4 Pro and M100/RedEdge-M missions suffered from uncalibrated errors, especially in the southeast part of the mission area farthest from the launch site. Uncalibrated images cause missing data in point clouds and erroneous georeferencing of the orthoimage. Future investigation will be conducted in order to explore the best practices of flight configuration and standardized workflow of sUAS missions.

Specifically for 3D tree surveying, one challenge of low-cost sUAS application is the need for a bare-earth surface. As opposed to LiDAR, sUAS cameras only collect a single return from the landscape at any location. In areas with vegetation cover, the sUAS point cloud records the elevation of the topmost points of the canopy, which is directly used to extract the DSM. Since optical sensors are only poorly capable of penetrating the tree canopy, sUAS point clouds cannot reliably collect ground points in woodlands. Even in open areas, the points are heavily deteriorated by short vegetation, such as grasses, forbs, and shrubs. Therefore, this study relied on other sources of ground elevation in order to extract canopy height. Today, LiDAR data products at modest spatial resolutions (1.4 to $1.8 \mathrm{~m}$ ) have been collected in almost every county across the United States. Although the high cost and operational difficulty of LiDAR missions hinder their repetitive data collection, their approximate one-meter point spacing provides the most accurate digital bare-earth models in areas without rapid terrain change. With these LiDAR data products available, sUAS can be flexibly deployed for quantitative tree surveys. Recent lightweight LiDAR products have been available for sUAS payloads. However, these products often have costs in the range of USD 50-100k, and are therefore too expensive for most operational sUAS deployments.

The dense, closed-canopy cover of overgrown forests poses further challenges for 3D tree surveying. This experiment concurs with past studies (Popescu and Wynn 2004; Jaafar et al. 2018) that the local maxima approach to identifying individual treetops works better for trees that are relatively isolated. This study also demonstrates that conifers are easier to delineate, because their crowns are often circular and symmetrical with single treetops. Deciduous trees, such as tulip poplar and black gum, present more complex, irregular crowns that may contain multiple local maxima. In dense stands, deciduous trees tend to overlap one another, forming a continuous canopy cover of multiple trees. This feature affects crown delineation with the inverse watershed segmentation approach. Both the local maxima and watershed segmentation approaches rely solely on the CHM data. As demonstrated in the subset area in Figure 9, the extracted tree crowns do not follow regular, rounded crown boundaries as we visually depict. For future research, spectral information from the orthoimages could be examined that may help to refine crown delineation. Nevertheless, this study demonstrates the high potential of sUAS 
remote sensing in quantitative field surveying. For the specific applications in this study, the sUAS-assisted dam inspection provides $\mathrm{cm}$-level 3D visualization of trees growing on the dam downslope. Older trees with taller, larger tree crowns are thus inventoried for further risk assessment. Earthen dams are usually small in size and, therefore, the sUAS mission can be fulfilled within 10 to 20 minutes at each dam. This process offers improved time and cost efficiency and personnel safety compared to traditional walkthrough field procedures. The sUAS-based tree survey inventory is also valuable information in other activities such as forest management and wildlife habitat conservation. Owning to its fine spatial details, time efficiency, and flexibility in data acquisition, sUAS remote sensing could fill the gap between traditional remote sensing and intensive field investigation in monitoring our ever-changing natural environment.

\section{Conclusions}

This study explored multiple sUAS missions to test the feasibility and procedure for 3D tree surveying of dense woodland on an earthen dam. For each mission, the orthoimage and point cloud were extracted to reconstruct the 3D canopy, which was further analyzed to measure tree heights and to outline tree crowns. The comparison study confirms that sUAS point clouds can stably build a canopy height model (CHM), with which treetops can be extracted using the local maxima approach and tree crowns can be outlined via watershed segmentation. In closed-canopy conditions, LiDAR is an essential source of bare-earth surfaces in the procedure. Among the drones tested in this study, the Phantom 4 Pro at higher flight altitudes is recommended for operational tree surveying. The M100/RedEdge-M achieves higher accuracy in $(x, y, z)$ positioning and tree height extraction (RMSE $=1 \mathrm{~m}$ ), but the improvement could be outweighed by its cost and complicated deployment procedure. The Mavic Pro fails to serve as a reliable tool for tree surveying, especially in dense forests.

Our experiments indicate that sUAS provide a timely and efficient means of 3D tree surveying for assessment of tree overgrowth to assist in dam safety inspection. The procedure could be adapted for other applications in quantitative landscape mapping. With the rapid development of sUAS technology, sUAS remote sensing could play a more reliable role in monitoring our living environment.

Author Contributions: Conceptualization, C.W. and M.E.H.; methodology, C.W.; data collection and processing, C.W., M.E.H. and G.M.; writing and editing, C.W. and M.E.H. All authors have read and agreed to the published version of the manuscript.

Funding: This research received no external funding.

Acknowledgments: This work was supported by the ASPIRE-II Program from the Office of the Vice President for Research at University of South Carolina (UofSC). The authors would like to thank Inthuorn Sasanakul and Herrick Brown at UofSC for their assistance in field experiments. This work could not have been completed without the support of Robert Livingston, who granted us access to his property of Sweet Bay Pond Dam.

Conflicts of Interest: The authors declare no conflict of interest.

\section{References}

1. National Inventory of Dams (NID). The 2018 National Inventory of Dams. 2018. Available online: http:/ / nid.usace.army.mil (accessed on 4 December 2020).

2. Rahmstorf, S. Rising hazard of storm-surge flooding. Proc. Natl. Acad. Sci. USA 2017, 114, 11806-11808. [CrossRef] [PubMed]

3. Vecchi, G.A.; Knutson, T.R. Historical Changes in Atlantic Hurricane and Tropical Storms. 2018. Available online: https: //www.gfdl.noaa.gov / historical-atlantic-hurricane-and-tropical-storm-records / (accessed on 4 December 2020).

4. Sasanakul, I.; Gassman, S.; Pierce, C.; Ovalle, W.; Starcher, R.; Gheibi, E.; Rahman, M. Dam Failure from the October 2015 Historic Flood Event in South Carolina, Asce Geotech. Spec. Publ. (GSP) 2017, 278, 244-254.

5. SC Department of Health and Environment Control (SDHEC). The State of the Dams: Investment in the Protection of South Carolina's People, Natural Resources, and Infrastructure through Dam Safety-A Report on the State of Dam Safety in South Carolina. 2020. Available online: https:/ / scdhec.gov / BOW/dams-reservoirs (accessed on 4 December 2020). 
6. Federal Emergency Management Agency (FEMA). Technical Manual for Dam Owners: Impacts of Plants on Earthen Dams, FEMA Document 534. 2005. Available online: https:/ / www.fema.gov/media-library-data/20130726-1446-20490-2338/fema-534.pdf (accessed on 30 December 2020).

7. Andersen, H.E.; Mcgaughey, R.S.; Reutebuch, E. Estimating forest canopy fuel parameters using LIDAR data. Remote Sens. Environ. 2005, 94, 441-449. [CrossRef]

8. Amiri, N.; Yao, W.; Heurich, M.; Krzystek, P.; Skidmore, A.K. Estimation of regeneration coverage in a temperate forest by 3D segmentation using airborne laser scanning data. Int. J. Appli. Earth Obs.. Geoinf. 2016, 52, 252-262. [CrossRef]

9. Morgan, G.; Hodgson, M.E.; Wang, C. Using sUAS-derived point cloud to supplement LiDAR returns for improved canopy height model on earthen dams. Pap. Appl. Geogr. 2020, 6, 436-448. [CrossRef]

10. Jensen, J.R. Drone Aerial Photography and Videography: Data collection and image interpretation. 2017 (e-book). Available online: https: / / www.jensendroneaerialphotographyvideography.com/ (accessed on 25 February 2021).

11. Gundlach, J. Civil and Commercial Unmanned Aircraft Systems; AIAA Education Series; American Institute of Aeronautics and Astronautics: Reston, VA, USA, 2016. [CrossRef]

12. Dandois, J.P.; Ellis, E.C. Remote sensing of vegetation structure using computer vision. Remote Sens. 2010, 2, 1157-1176. [CrossRef]

13. Westoby, M.J.; Brasington, J.; Glasser, N.F.; Hambrey, M.J.; Reynolds, J.M. Structure-from-Motion' photogrammetry: A low-cost, effective tool for geoscience applications. Geomorphology 2012, 179, 300-314. [CrossRef]

14. Seitz, S.M.; Curless, B.; Diebel, J.; Scharstein, D.; Szeliski, R. Proceedings of the 2006 IEEE Computer Society Conference on Computer Vision and Patter Recognition (CVPR'06), New York, NY, USA, 17-22 June 2006; Volume 1, pp. 519-526.

15. Hyyppä, J.; Hyyppä, H.D.; Leckie, F.; Gougeon, F.; Yu, X.; Maltamo, M. Review of methods of small-footprint airborne laser scanning for extracting forest inventory data in boreal forests. Int. J. Remote Sens. 2008, 29, 1339-1366. [CrossRef]

16. Dalponte, M.; Reyes, F.; Kandare, K.; Gianelle, D. Delineation of individual tree crowns from ALS and hyperspectral data: A comparison among four methods. Eur. J. Remote Sens. 2015, 48, 365-382. [CrossRef]

17. Ferraz, A.; Bretar, F.; Jacquemoud, S.; Gonçalves, L.; Pereira, L.; Tomé, M.; Soares, P. 3-D mapping of a multi-layered Mediterranean forest using ALS data. Remote Sens. Environ. 2012, 122, 210-223.

18. Ferraz, A.; Saatchi, S.; Mallet, C.; Meyer, V. Lidar detection of individual tree size in tropical forests. Remote Sens. Environ. 2016, 183, 318-333. [CrossRef]

19. Jaafar, W.S.W.M.; Woodhouse, I.H.; Silva, C.A.; Omar, H.; Maulud, K.N.A.; Hudak, A.T.; Klauberg, C.; Cardil, A.; Mohan, M. Improving individual tree crown delineation and attributes estimation of tropical forests using airborne LiDAR data. Forests 2018, 9, 759. [CrossRef]

20. Panagiotidis, D.; Abdollahnejad, A.; Surový, P.; Chiteculo, V. Determining tree height and crown diameter from high-resolution UAV imagery. Int. J. Remote Sens. 2016, 38, 2392-2410. [CrossRef]

21. Mohan, M.; Silva, C.A.; Klauberg, C.; Jat, P.; Catts, G.; Cardil, A.; Hudak, A.T.; Dia, M. Individual tree detection from unmanned aerial vehicle (UAV) derived canopy height model in an open canopy mixed conifer forest. Forests 2017, 8, 340. [CrossRef]

22. Dong, X.; Zhang, Z.; Yu, R.; Tian, Q.; Zhu, X. Extraction of information about individual trees from high-spatial-resolution UAV-acquired images of an orchard. Remote Sens. 2020, 12, 133. [CrossRef]

23. Federal Aviation Administration (FAA). Fact Sheet - Small Unmanned Aircraft Systems (UAS) Regulations (Part 107). Released on 6 October 2020. Available online: https://www.faa.gov/news/fact_sheets (accessed on 21 January 2021).

24. Emlid Reach RS2 Docs, 2021. Precise Point Positioning (PPP). Available online: https://docs.emlid.com/reachrs2/common/ tutorials/ppp-introduction/ (accessed on 25 February 2021).

25. National Geodetic Survey (NGS). NOAA's Online Positioning User Service (OPUS). 2021. Available online: https: / www.ngs. noaa.gov/INFO/OnePagers/OPUSOnePager.pdf (accessed on 25 February 2021).

26. U.S. Geological Survey (USGS). USGS Lidar Point Cloud (LPC) SC_LexingtonCo_2010_000827 2014-0913 LAS, U.S. Geological Survey. Published on 13 September 2014.

27. SC Department of Natural Resources (SCDNR). LiDAR and Related Data Products. 2015. Available online: http:/ / www.dnr.sc. gov/GIS/lidar.html (accessed on 20 February 2019).

28. Heidemann, H.K. Lidar Base Specification, V1.3. U.S. Geological Survey (USGS) Techniques and Methods. Chapter B4, in Book 11Collection and Delineation of Spatial Data. 101 p. Revised February 2018. 2018. Available online: https://doi.org/10.3133/tm11b4 (accessed on 21 January 2021).

29. Mielcarek, M.; Stereńczak, K.; Khosravipour, A. Testing and evaluating different LiDAR-derived canopy height model generation methods for tree height estimation. Int. J. Appl. Earth Obs. Geoinf. 2018, 71, 132-143. [CrossRef]

30. Smith, H.C. Height of Tallest Saplings in 10-Year Old Appalachian Hardwood Clearcuts. Forest Service Research Paper NE-381, Forest Service, U.S. Department of Agriculture, Northeastern Forest Experiment Station. 1977. Available online: https://www.fs.fed.us/ne/newtown_square/publications/research_papers/pdfs/scanned/OCR/ne_rp381.pdf (accessed on 25 February 2021).

31. Popescu, S.C.; Wynne, R.H. The trees in the forest. Photogramm. Eng. Remote Sens. 2004, 70, 589-604.

32. Vincent, L.; Soille, P. Watersheds in digital spaces: An efficient algorithm based on immersion simulations, IEEE Trans. Pattern Anal. Mach. Intell. 1991, 13, 583-598. [CrossRef] 
33. Meyer, F.; Beucher, S. Morphological segmentation. J. Vis. Commun. Image Represent. 1990, 1, 21-46. [CrossRef]

34. U.S. Forest Service (USFS). Unmanned Aircraft System (UAS) - Forest Service Standards for UAS Operations. U.S. Department of Agriculture. 2020. Available online: https://www.fs.usda.gov/sites/default/files/2020-07/Forest $\% 20$ Service $\% 20$ Standards $\%$ 20for\%20UAS\%20Operations\%2007012020.pdf (accessed on 25 February 2021). 